\title{
SELECTED TOPICS IN INFORMATION AND CODING THEORY
}




\section{Series on Coding Theory and Cryptology}

Editors: Harald Niederreiter (National University of Singapore, Singapore) and San Ling (Nanyang Technological University, Singapore)

\section{Published}

Vol. 1 Basics of Contemporary Cryptography for IT Practitioners by B. Ryabko and A. Fionov

Vol. 2 Codes for Error Detection by T. Kløve

Vol. 3 Advances in Coding Theory and Cryptography eds. T. Shaska et al.

Vol. 4 Coding and Cryptology eds. Yongqing Li et al.

Vol. 5 Advances in Algebraic Geometry Codes eds. E. Martínez-Moro, C. Munuera and D. Ruano

Vol. 6 Codes over Rings ed. P. Solé

Vol. 7 Selected Topics in Information and Coding Theory eds. I. Woungang, S. Misra and S. Chandra Misra 


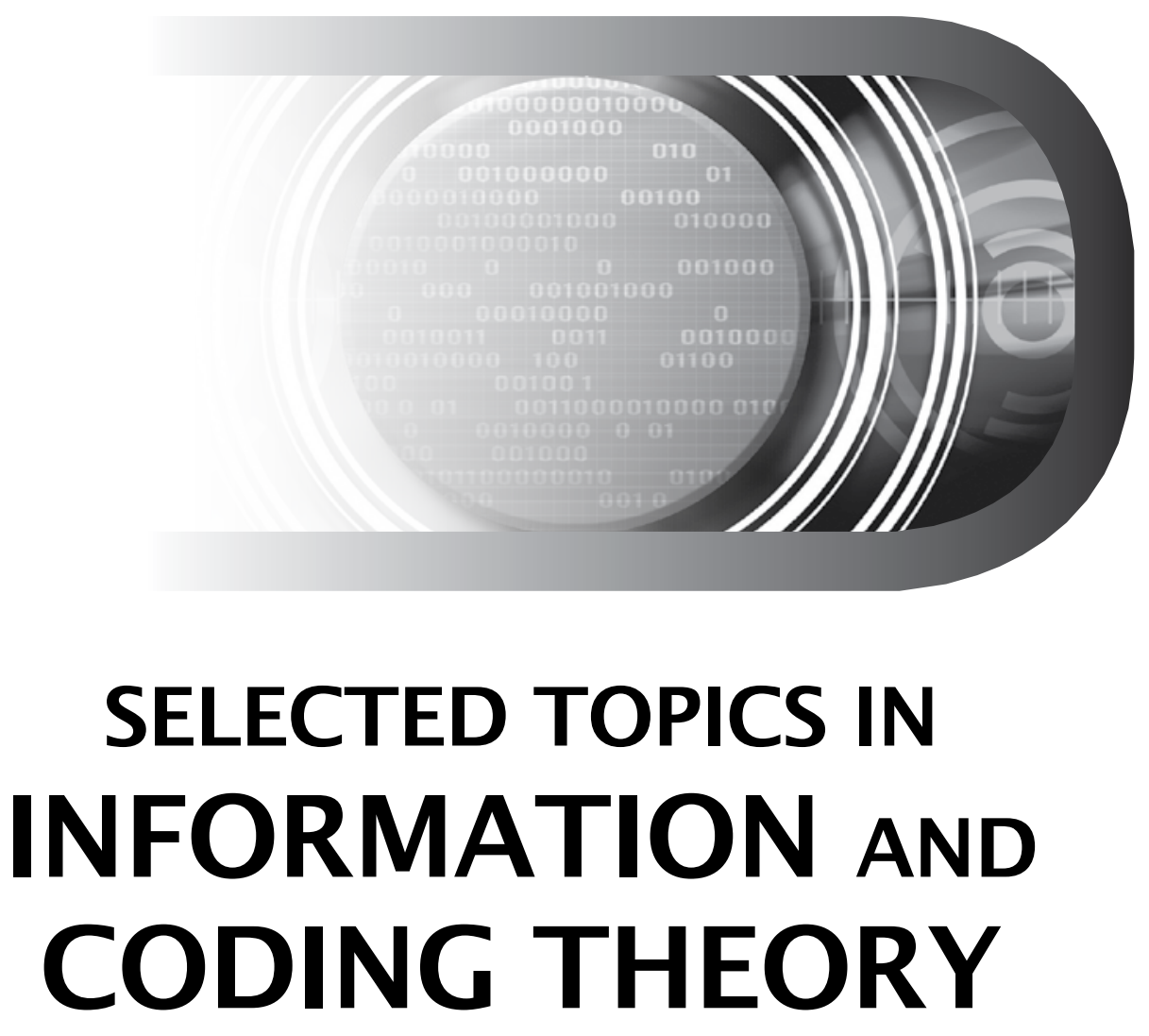

Editors

I. Woungang

Ryerson University, Canada

S. Misra

Indian Institute of Technology, Kharagpur, India

S. C. Misra

State University of New York at Buffalo, USA 
Published by

World Scientific Publishing Co. Pte. Ltd.

5 Toh Tuck Link, Singapore 596224

USA office: 27 Warren Street, Suite 401-402, Hackensack, NJ 07601

UK office: 57 Shelton Street, Covent Garden, London WC2H 9HE

\section{British Library Cataloguing-in-Publication Data}

A catalogue record for this book is available from the British Library.

\section{SELECTED TOPICS IN INFORMATION AND CODING THEORY Series on Coding Theory and Cryptology - Vol. 7}

Copyright (C) 2010 by World Scientific Publishing Co. Pte. Ltd.

All rights reserved. This book, or parts thereof, may not be reproduced in any form or by any means, electronic or mechanical, including photocopying, recording or any information storage and retrieval system now known or to be invented, without written permission from the Publisher.

For photocopying of material in this volume, please pay a copying fee through the Copyright Clearance Center, Inc., 222 Rosewood Drive, Danvers, MA 01923, USA. In this case permission to photocopy is not required from the publisher.

ISBN-13 978-981-283-716-5

ISBN-10 981-283-716-7

Typeset by Stallion Press

Email: enquiries@stallionpress.com

Printed in Singapore. 


\section{Dedicated to}

Isaac's wife: Clarisse and sons: Clyde, Lenny, Kylian Subhas's daughter: Devarati

Sudip's son: Devadeep 
This page intentionally left blank 


\section{PREFACE}

\section{Overview and Goals}

Information and Coding Theory research and applications are undergoing rapid advancements. The last few years have witnessed rapid advancements in Information and Coding Theory research and applications. This book provides a comprehensive guide to selected topics, both ongoing and emerging, in Information and Coding Theory. Consisting of contributions from well known and high profile researchers in their respective specialties, topics that are covered include applications of coding theory to computational complexity, algebraic combinatorics in coding theory, codes construction and existence, source coding, channel capacity, network coding, and few other selected topics in Information and Coding Theory research.

The book has been prepared keeping in mind that it needs to prove itself to be a valuable resource dealing with both the important core and the specialized issues in Information and Coding Theory. We hope that it will be a valuable reference for students, instructors, researchers, engineers, and industry practitioners in these fields. All of the chapters are integrated in a manner that renders the book as a supplementary reference volume and/or textbook for use in both undergraduate and graduate courses on Information and Coding Theory. Each chapter is of an expository, but also of a scholarly, tutorial, or survey style, on a particular topic within the scope of Information and Coding Theory.

\section{Organization and Features}

The book is organized into 15 chapters, each chapter written by topical area experts. These chapters are grouped into four parts. 
Part $\mathbf{1}$ is devoted to the applications of coding theory to computational complexity, and is composed of three chapters: Chaps. 1-3. Chapter 1 discusses several theoretical methods for analyzing the linear complexity and related complexity measures and proposes several classes of interesting sequences with high linear complexity. Chapter 2 focuses on the construction of high coding gain lattices with low decoding complexity from good codes in larger dimensions, and proposes a possible lattice construction with high coding gain using turbo codes and Low Density Parity Check codes. Chapter 3 is dedicated to the issues of cooperative communication in wireless relay networks. Various constructions of the distributed space-time block codes with low maximum-likelihood decidability are surveyed, and new upper bounds on the maximum rate of certain classes of single-symbol decodable distributed space-time block codes are proposed.

Part 2 focuses on methods of algebraic combinatorics in coding theory, and methods of codes construction and existence. It is composed of four chapters: Chaps. 4-7. Chapter 4 discusses in-depth the interplay of coding theory and algebraic combinatorics, focusing on the interaction of codes with combinatorial designs. Chapter 5 discusses ways and results in which to define, construct, prove theorems, and analyze codes from group rings in general, using both zero-divisor and units within a group ring. The codes derived are described as either zero-divisor or unit-derived codes. Chapter 6 is a continuation of the work initiated in Chapter 5, by presenting a new algebraic group ring-based method for constructing codes with no short cycles in the check matrix, and a general algebraic method for constructing Low Density Parity Check codes with no short cycles. Chapter 7 presents the construction of some well-known classes of algebraic block codes, and discusses recent generalizations of quasi-cyclic codes, as well as some algebraic and combinatorial methods of obtaining new codes from existing ones.

Part 3 centers on source coding, channel capacity, and network coding issues. It is composed of three chapters: Chaps. 8-10. Chapter 8 introduces a new approach to estimation, prediction and hypothesis testing for time series based on ideas of universal coding or universal data compression. Chapter 9 presents a subjective approach to network coding, which is concerned with the deterministic multicast encoding of cyclic networks. This topic is presented at a level of detail that is not found elsewhere in the literature. Chapter 10 addresses the problem of transmission of several distributed sources over a multiple access channel with side information 
at the sources and the decoder, and proposes a joint source channel coding approach, which generalizes previous results available on the studied problem.

Part 4 addresses other selected topics in Information and Coding Theory, and is composed of five chapters; Chaps. 11-15. Chapter 11 presents a tutorial exposition of Low Density Parity Check codes. Chapter 12 focuses on some selected topics in the theory of variable length codes, including connections with codes for constrained channels and sources. Chapter 13 deals with decoding techniques and methods for finding the minimum distance of linear codes by means of Gröbner bases. Chapter 14 presents an overview of cooperative diversity, along with latest advances and open issues in this evolving field. In Chap. 15, algebraic coding theory is used as an alternative way to define secure cryptographic primitives.

We list below some of the important features of this book, which, we believe, would make it a valuable resource for our readers:

- This book is designed, in structure and content, to aid the learning process with the intention of making the book useful at all learning levels.

- Most of the chapters of the book are authored by prominent academicians/researchers, practitioners, in Information and Coding Theory that have been working with these topics for quite a few years now and have thorough understanding of the concepts.

- The authors of this book are distributed in a large number of countries and most of them are affiliated with institutions of worldwide repute. This gives this book an international flavor.

- Most of the chapters in this book have a distinct section providing direction for future research, which, particularly, targets researchers working in these areas. We believe that this section should provide insight to the researchers about some of the current research issues.

- The authors of each chapter have attempted to provide a comprehensive bibliography, which should greatly help the readers interested further to dig into the topics.

- Most of the chapters of this book have a separate section outlining thoughts for practitioners. We believe that this section in every chapter will be particularly useful for industry practitioners working directly with the practical aspects behind enabling these technologies in the field.

- All chapters, except one, provide a set of questions at the end that can help in assessing the understanding of the readers. In most chapters, solutions are provided to some of these questions. 
- To make the book useful for pedagogical purposes, all chapters of the book have a corresponding set of presentation slides. The slides can be obtained as a supplementary resource by contacting the publisher, World Scientific, Singapore.

We have made attempts in all possible ways we could to make the different chapters of the book look as much coherent and synchronized as possible. However, it cannot be denied that due to the fact chapters were written by different authors, it was not fully possible to fully achieve this task. We believe that this is a limitation of most edited books of this sort.

\section{Target Audience}

The book is written by primarily targeting the student community. This includes the students of all levels - those getting introduced to these areas, those having an intermediate level of knowledge of the topics, and those who are already knowledgeable about many of the topics. To keep up with this goal, we have attempted to design the overall structure and content of the book in such a manner that makes it useful at all learning levels. To aid in the learning process, almost all chapters have a set of questions at the end of the chapter. Also, in order that teachers can use this book for classroom teaching, the book also comes with presentation slides and sample solutions to exercise questions, which are available as supplementary resources.

The secondary audience for this book is the research community, whether they are working in the academia or in the industry. To meet the specific needs to this audience group, certain chapters of the book provide directions for future research.

Finally, we have also taken into consideration the needs to those readers, typically from the industries, who have quest for getting insight into the practical significance of the topics, i.e. how the spectrum of knowledge and the ideas are relevant for real-life applications of coding and information theory.

\section{Supplementary Resources}

As mentioned earlier, the book comes with presentation slides for each chapter, which can be used for classroom instruction by teachers.

Teachers can contact the publisher, World Scientific, Singapore, to get access to these resources. 


\title{
Acknowledgments
}

We are extremely thankful to the 25 authors of the 15 chapters of this book, who have worked very hard to bring this unique resource forward for help of the student, researcher, and practitioner community. The authors were very much interactive at all stages of preparation of the book from initial development of concept to finalization. We feel it is contextual to mention that as the individual chapters of this book are written by different authors, the responsibility of the contents of each of the chapters lies with the concerned authors.

We are also very much thankful to our colleagues in the World Scientific publishing and marketing teams, in particular, Ms. Kimberly Chua, Ms. Chelsea Chin, and Ms. Mei Kian, who tirelessly worked with us and guided us in the publication process. Special thanks also go to them for taking special interest in publishing this book, considering the current worldwide market needs for such a book.

Finally, we would like to thank our parents, Mr. J. Sime, Ms. C. Seupa, Prof. J.C. Misra, Ms. Shorasi Misra, our wives Clarisse, Satamita, and Sulagna, and our children Clyde, Lenny, Kylian, Babai, and Tultuli, for the continuous support and encouragement they offered during the course of this project.

\author{
Dr. Isaac Woungang \\ Toronto, ON, Canada \\ Dr. Subhas Chandra Misra \\ Kanpur, UP, India \\ Dr. Sudip Misra \\ Kharagpur, WB, India
}


This page intentionally left blank 


\section{CONTENTS}

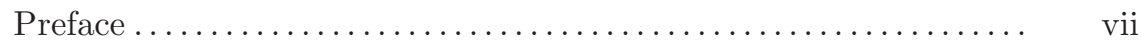

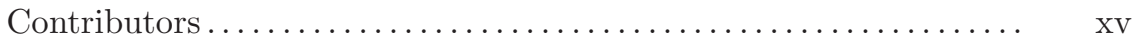

Part 1: Applications of Coding Theory to Computational Complexity............................... 1

Chapter 1: Linear Complexity and Related Complexity Measures.. $\quad 3$ Arne Winterhof

Chapter 2: Lattice and Construction of High Coding Gain Lattices from Codes..................... 41 Mohammd-Reza Sadeghi

Chapter 3: Distributed Space-Time Codes with Low ML Decoding Complexity......................... $\quad 77$ G. Susinder Rajan and B. Sundar Rajan

Part 2: Methods of Algebraic Combinatorics in Coding Theory/Codes Construction and Existence....... 119

Chapter 4: Coding Theory and Algebraic Combinatorics ......... 121 Michael Huber

Chapter 5: Block Codes from Matrix and Group Rings ............ 159 Paul Hurley and Ted Hurley

Chapter 6: LDPC and Convolutional Codes from Matrix

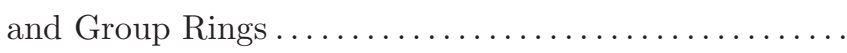
Paul Hurley and Ted Hurley 
Chapter 7: Search for Good Linear Codes in the Class of Quasi-Cyclic and Related Codes.................

Nuh Aydin and Tsvetan Asamov

\section{Part 3: Source Coding/Channel Capacity/}

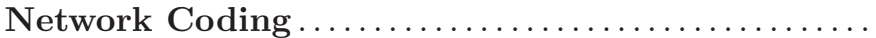

Chapter 8: Applications of Universal Source Coding to Statistical Analysis of Time Series......................... 289 Boris Ryabko

Chapter 9: Introduction to Network Coding for Acyclic and Cyclic Networks............................ Ángela I. Barbero and Øyvind Ytrehus

Chapter 10: Distributed Joint Source-Channel Coding on a Multiple Access Channel ................... Vinod Sharma and R. Rajesh

\section{Part 4: Other Selected Topics in Information} and Coding Theory $\ldots \ldots \ldots \ldots \ldots \ldots \ldots \ldots \ldots \ldots$

Chapter 11: Low-Density Parity-Check Codes and the Related Performance Analysis Methods ................... Xudong $M a$

Chapter 12: Variable Length Codes and Finite Automata ......... 505 Marie-Pierre Béal, Jean Berstel, Brian H. Marcus, Dominique Perrin, Christophe Reutenauer and Paul H. Siegel

Chapter 13: Decoding and Finding the Minimum Distance with Gröbner Bases: History and New Insights....... Stanislav Bulygin and Ruud Pellikaan

Chapter 14: Cooperative Diversity Systems for Wireless Communication .............................. Murat Uysal and Muhammad Mehboob Fareed

Chapter 15: Public Key Cryptography and Coding Theory ........ 663 Pascal Véron 


\title{
CONTRIBUTORS
}

\author{
Nuh Aydin \\ Department of Mathematics \\ Kenyon College, Gambier, OH 43022, USA \\ aydinn@kenyon.edu
}

\section{Tsvetan Asamov}

Department of Mathematics

Kenyon College, Gambier, OH 43022, USA

asamovt@kenyon.edu

\section{Marie-Pierre Béal}

Institut Gaspard-Monge (IGM)

Université Paris-Est

77454 Marne-la-Vallée Cedex 2, Paris, France

beal@univ-mlv.fr

\section{Jean Berstel}

Institut Gaspard-Monge (IGM), Université Paris-Est

77454 Marne-la-Vallée Cedex 2, Paris, France

berstel@univ-mlv.fr

\section{Dominique Perrin}

Institut Gaspard-Monge (IGM)

Université Paris-Est

77454 Marne-la-Vallée Cedex 2, Paris, France

dominique.perrin@esiee.fr

\section{Brian H. Marcus}

University of British Columbia

B.C., Vancouver, Canada

marcus@math.ubc.ca 


\section{Christophe Reutenauer}

LaCIM, Université du Québec à Montréal

Montréal, Canada

reutenauer.christophe@uqam.ca

\section{Paul H. Siegel}

Department of Electrical and Computer Engineering University of California at San Diego, San Diego, USA psiegel@ucsd.edu

\section{Boris Ryabko}

Siberian State University of Telecommunications

and Informatics and Institute of Computational Technology

of Siberian Branch of Russian Academy of Science, Russia boris@ryabko.net

\section{Stanislav Bulygin}

Department of Mathematics

University of Kaiserslautern

P.O. Box 3049, 67653 Kaiserslautern, Germany

bulygin@mathematik.uni-kl.de

\section{Ruud Pellikaan}

Department of Mathematics and Computing Science

Eindhoven University of Technology, P.O. Box 513

NL-5600 MB, Eindhoven, The Netherlands

g.r.pellikaan@tue.nl

\section{Michael Huber}

Institut für Mathematik, Technische Universität Berlin, Straße des 17. Juni 136, D-10623, Berlin, Germany mhuber@math.TU-Berlin.DE

\section{Murat Uysal}

Department of Electrical and Computer Engineering University of Waterloo, Waterloo, Ontario, Canada, N2L3G1 muysal@ece.uwaterloo.ca

\section{Muhammad Mehboob Fareed}

Department of Electrical and Computer Engineering University of Waterloo, Waterloo, Ontario, Canada mmfareed@ece.uwaterloo.ca 


\section{Angela I. Barbero}

Department of Applied Mathematics

University of Valladolid

47011 Valladolid, Spain

angbar@wmatem.eis.uva.es

\section{Oyvind Ytrehus}

Department of Informatics

University of Bergen, N-5020 Bergen, Norway

oyvind@ii.uib.no

\section{G. Susinder Rajan}

Department of Electrical Communication Engineering Indian Institute of Science, Bangalore 560012, India susinder@ece.iisc.ernet.in

\section{B. Sundar Rajan}

Department of Electrical Communication Engineering Indian Institute of Science, Bangalore 560012, India bsrajan@ece.iisc.ernet.in

\section{Mohammd-Reza Sadeghi}

Faculty of Mathematics and Computer Science Amirkabir University of Technology Hafez Ave.

Tehran, Iran

msadeghi@aut.ac.ir

\section{Vinod Sharma}

Department of Electrical Communication Engineering Indian Institute of Science, Bangalore 560012, India vinod@ece.iisc.ernet.in

\section{R. Rajesh}

Department of Electrical Communication Engineering Indian Institute of Science, Bangalore 560012, India rajesh@pal.ece.iisc.ernet.in

\section{Paul Hurley}

IBM Research

Zurich Research Laboratory, Switzerland pah@zurich.ibm.com 


\section{Ted Hurley}

Department of Mathematics

National University of Ireland

Galway, Ireland

ted.hurley@nuigalway.ie

\section{Pascal Véron}

Institut de Mathématiques de Toulon

Université du Sud Toulon-Var

Toulon, France

veron@univ-tln.fr

\section{Xudong Ma}

Department of Electrical and Computer Engineering University of Waterloo, Waterloo

Ontario N2L 3G1, Canada

x3ma@bbcr.uwaterloo.cay 